\title{
Avaliação do protocolo sanitário contra a COVID-19 adotado por uma Instituição de Ensino Superior na Cidade de Manaus
}

\author{
Evaluation of the health protocol against COVID-19 adopted by a Higher Education Institution in
} Manaus City

Evaluación del protocolo de salud contra COVID-19 aprobado por una Institución de Educación Superior de la Ciudad de Manaus

Nelson Felipe de Albuquerque Lins Neto ORCID: https://orcid.org/0000-0002-5810-4836 Faculdade Salesiana Dom Bosco, Brasil E-mail: linsneton@gmail.com

Paula Bonates Bessa

ORCID: https://orcid.org/0000-0002-6067-6665 Fundação de Medicina Tropical, Brasil E-mail: paaulabonates@hotmail.com Elio Oliveira da Silva ORCID: https://orcid.org/0000-0002-6794-2508 Hapvida Assistência Médica Ltda., Brasil E-mail: elio_os@hotmail.com

Laura Marques Franco

ORCID: https://orcid.org/0000-0002-2244-4249 Centro Universitário Fametro, Brasil E-mail: lauramfranco18@gmail.com Álefe Lopes Viana ORCID: https://orcid.org/0000-0003-4844-5693 Instituto Federal de Educação, Ciência e Tecnologia do Amazonas, Brasil E-mail: alefe.viana@gmail.com

Roberta Monique da Silva Santos ORCID: https://orcid.org/0000-0002-7624-4824 Faculdade Salesiana Dom Bosco, Brasil E-mail: paaulabonates@hotmail.com

Neliton Marques da Silva

ORCID: https://orcid.org/0000-0002-6812-729X Universidade Federal do Amazonas, Brasil E-mail:nmerinato@gmail.com

\begin{abstract}
Resumo
Ao final de 2019 e ao longo de 2020 o mundo deparou-se com uma doença causada pelo novo coronavírus, levando muitos governos e instituições a repensarem suas formas de atuarem para controlar esta pandemia. $\mathrm{O}$ objetivo desse trabalho foi avaliar a o protocolo sanitário contra a COVID-19 adotado por uma Instituição de Ensino Superior de Manaus, verificando a percepção da comunidade acadêmica, o atendimento às normas previstas pelos órgãos competentes, os principais aspectos adotados e a progressão da doença no local. Foi realizado um estudo de caso com levantamentos por meio de pesquisa aplicada com uso de questionário estruturado para avaliar à evolução da doença, a percepção dos participantes, o protocolo ambiental e sanitário adotado, verificando os principais aspectos relacionados à contenção da disseminação desse vírus bem como visitas à instituição para verificar o atendimento às normas estabelecidas pelo protocolo, identificando as medidas elencadas e realizadas pela Instituição. As ações praticadas foram positivas e contribuíram para o controle da doença na instituição, fazendo a comunidade acadêmica se sentisse segura. Foram observadas algumas poucas não conformidades no cumprimento do protocolo, devendo a instituição intensificar a fiscalização. O retorno presencial divide opiniões, sendo preferido o modo "semipresencial" (50\% em sala e 50\% remota). Em virtude da crise na saúde em Manaus, recomenda-se que as aulas sejam realizadas de forma integralmente remotas enquanto os números de casos não retornarem até os níveis mais baixos observados pelas autoridades e a vacinação da população não progredir conforme o esperado.
\end{abstract}

Palavras-chave: Coronavírus; Saúde coletiva; Gestão ambiental. 


\begin{abstract}
At the end of 2019 and throughout 2020 the world faced a disease caused by the new coronavirus, leading many governments and institutions to rethink their ways of working to control this pandemic. The objective of this work was to evaluate the health protocol against COVID-19 adopted by a Higher Education Institution in Manaus, verifying the perception of the academic community, the compliance with the norms foreseen by Organs competent bodies, the main aspects adopted and the disease progression in the place. A case study was carried out with surveys through applied research using a structured questionnaire to assess the evolution of the disease, the perception of the participants, the environmental and health protocol adopted, verifying the main aspects related to the containment of the spread of this virus as well as visits to the institution to verify compliance with the rules established by the protocol, identifying the measures listed and carried out by the institution. The actions taken were positive and contributed to the control of the disease in the institution, making the academic community feel safe. A few nonconformities were observed in compliance with the protocol, and the institution should intensify the inspection. Faceto-face feedback divides opinions, with the "semi-face" mode being preferred (50\% in class and 50\% remote). Due to the health crisis in Manaus, it is recommended that classes be held in a completely remote manner while the numbers of cases do not return to the lowest levels observed by the authorities and the vaccination of the population does not progress as expected.
\end{abstract}

Keywords: Coronavirus; Collective health; Environmental management.

\title{
Resumen
}

A finales de 2019 y a lo largo de 2020 el mundo enfrentó una enfermedad provocada por el nuevo coronavirus, lo que llevó a muchos gobiernos e instituciones a repensar sus formas de trabajar para controlar esta pandemia. El objetivo de este trabajo fue evaluar el protocolo de salud contra COVID-19 adoptado por una Institución de Educación Superior en Manaus, verificando la percepción de la comunidad académica, el cumplimiento de las normas previstas por los órganos competentes, los principales aspectos adoptados y la enfermedad. progresión en el lugar. Se realizó un estudio de caso con encuestas a través de investigación aplicada mediante un cuestionario estructurado para evaluar la evolución de la enfermedad, la percepción de los participantes, el protocolo ambiental y sanitario adoptado, verificando los principales aspectos relacionados con la contención de la propagación de este virus. así como visitas a la institución para verificar el cumplimiento de las normas establecidas por el protocolo, identificando las medidas enumeradas y ejecutadas por la institución. Las acciones realizadas fueron positivas y contribuyeron al control de la enfermedad en la institución, haciendo que la comunidad académica se sienta segura. Se observaron algunas no conformidades en el cumplimiento del protocolo y la institución debe intensificar la inspección. La retroalimentación cara a cara divide las opiniones, prefiriéndose el modo "semi-cara" (50\% en el aula y 50\% a distancia). Debido a la crisis de salud en Manaus, se recomienda que las clases se realicen de manera completamente remota mientras el número de casos no regrese a los niveles más bajos observados por las autoridades y la vacunación de la población no progrese como se esperaba.

Palabras clave: Coronavirus; Salud colectiva; Gestión ambiental.

\section{Introdução}

Ao final do ano de 2019, o mundo foi sacudido com noticias de uma doença desconhecida, altamente contagiosa e potencialmente letal, oriunda da cidade de Wuhan, na China, evidenciando que 2020 poderia se tornar um dos anos mais difíceis em muitas décadas para a humanidade.

O causador foi identificado como sendo um RNA vírus zoonótico, da ordem Nidovirales, sendo isolados e descritos pela primeira vez entre 1937 e 1965, recebendo este nome em virtude da sua aparência na microscopia, semelhante a uma coroa, por isso, coronavírus (Lima, 2020).

A doença foi classificada como COVID-19 e estava sendo causada pelo vírus denominado SARS-CoV-2, da família Coronavirideae, sendo muitos destes amplamente distribuídos ao redor do mundo e não sendo exclusivos do homem, mas com ocorrências em diferentes espécies de animais como gatos, pássaros, cães e morcegos, tendendo a causar infecções respiratórias em humanos, sendo os mais conhecidos, até então, a síndrome respiratório aguda grave por corona vírus (SARS$\mathrm{CoV}$ ) e a síndrome respiratória do Oriente Médio (MERS-CoV), causando sintomas semelhantes aos de pneumonias mais graves com fatalidades em humanos entre 10 e $34 \%$ dos infectados, respectivamente (Ahmed, 2020).

A doença possui uma grande variedade de sintomas, sendo que os mais comuns ocorrem no início da doença, dentre os quais febre, tosse, mialgia, fadiga, produção de tosse seca, falta de ar (dispneia), evidencias de pneumonia viral e os menos comuns como sangue ao tossir (hemoptise), dor abdominal, diarreia, náuseas, vômitos, dores de garganta, congestão nasal, 
cefaleia dor de cabeça, tontura e consciência prejudicada, que se desenvolvem entre o dia da infecção e o início da doença, com incubação média de 5 a 6 dias apresentando sintomas em até 12 dias (Vieira et al., 2020).

Para combater e frear a evolução do vírus, diversas nações adotaram medidas das mais variadas como evitar espaços confinados como aviões, ônibus, metrôs, a utilização de mascaras, uso regular de álcool em gel e lavagem das mãos, bem como evitar lugares com alto fluxo de pessoas ou que pudessem causar aglomerações como feiras, mercados, shoppings, e até escolas, causando uma mudança significativa na forma de viver das pessoas em todo o planeta.

No entanto, mesmo com os governos informando a população das ações a serem adotadas para o combate ao novo coronavírus, ao longo de aproximadamente um ano, a Organização Mundial da Saúde (OMS) (2020), registrou a triste marca de quase 115 milhões de casos confirmados, aproximadamente 1,5\% da população mundial e 2.550 .500 mortes em mais de 223 países.

De acordo com o Ministério da Saúde (2020), considerando apenas o Brasil, este seria responsável por aproximadamente $10 \%$ de todos os casos de contaminação e de óbitos em todo o mundo, onde o Estado do Amazonas registrou 318.948 casos e 11.087 mortes, sendo o $15^{\circ}$ estado mais contaminado e o $5^{\circ}$ neste ranking macabro quando se compara o número de mortos pelo tamanho da população, sendo a capital amazonense a quinta cidade mais infectada e com maior número de mortos, 112.907 e 7.810, respectivamente, onde morreram mais pessoas nos primeiros dois meses de 2021 do que o ano inteiro de 2020 (G1AM, 2021), coincidindo com a mesma data, 04 de março de 2021, em que o Brasil registra o maior numero de mortos desde o começo da pandemia em um único dia, com 1.840 óbitos, sendo o dia anterior, o maior observado até então, indicando um viés de alta nos números da pandemia.

Ao largo de um ano, os governos, nos seus mais diferentes níveis, vem tomando medidas para amenizar os impactos sociais e econômicos que a pandemia trouxe consigo, seja através da doação de cestas básicas ou de programas de auxílios emergenciais, via doação de valores às famílias para mantê-las em casa, evitando, assim, novas contaminações e aumento da pressão sobre o sistema de saúde.

Apesar de bem intencionados, os recursos são finitos, impossibilitando mantê-los por período mais extenso.

Assim sendo, muitos governantes têm decretado o confinamento (lockdown) como um das medidas para o controle da pandemia, o que tem prejudicado diversos setores como a educação formal, técnica e superior.

De acordo com o Sindicato das Entidades Mantenedoras de Estabelecimentos de Ensino Superior no Estado de São Paulo (SEMESP) (2020), até abril desse ano, a evasão escolar foi de mais de 11\% enquanto a inadimplência aumentou em mais de $71 \%$ em comparação com o mesmo período do ano anterior, levando preocupação às mantenedoras dessas instituições e, potencialmente, a regredir dos atuais $37,4 \%$ de brasileiros entre 18 e 24 anos para menos de $15 \%$, números similares ao inicio da primeira década do século XXI, causando um atraso inestimável ao país e destruindo o sonho de mais de 1,6 milhões de estudantes (Oliveira, 2020).

Para evitar a parada total das atividades e o atraso dos conteúdos, muitas instituições de ensino tiveram que readequarse à nova realidade que se impôs, adotando medidas como aulas remotas com uso da rede mundial de computadores e flexibilizando as formas de se assistir, participar e interagir nas aulas presenciais, mediante protocolos preestabelecidos indicando a forma correta de atuar no ambiente institucional. No caso de países como a Somália, mais da metade das IES fecharam as portas e as que mantiveram, apontaram dificuldades diversas para permanecerem abertas. Muitas vezes em virtude dos custos adicionais para alunos, instituições e professores com ferramentas digitais ou conexão à internet, sem contar o principal fator de insatisfação que foi mencionado, como a dificuldade para dirimir dúvidas com os tutores por não estarem na sua presença (Mohamad, 2020).

Apesar da Organização Pan-Americana da Saúde (OPAS) e a Organização Mundial de Saúde (OMS) prestarem assistência ao Brasil em resposta à pandemia, através da Escola Nacional de Saúde Pública e suas Notas Técnicas que 
atualizam o panorama epidemiológico e ajudam a orientar Secretarias de Educação e de Saúde em suas decisões com atualização de informações, recomendações e protocolos para mitigar a disseminação do vírus e seus problemas na saúde da população, (FIOCRUZ, 2020), ruídos oficiais e não oficiais emergiram, dificultando o entendimento de como as instituições, de um modo geral, deveriam agir.

Além disso, a situação política instável do ponto de vista gerencial e a falta de determinação entre as instituições públicas responsáveis, fizeram com que muitas organizações desenvolvessem seus próprios protocolos a partir de informações fragmentadas de diversas instituições como a ONU, Secretarias de Saúde, de Meio Ambiente, de Educação, tanto estaduais quanto municipais, Ministério da Saúde, entre outros, resultando em protocolos dos mais diversos, dificultando sua rastreabilidade quanto a sua eficiência e, portanto, deixando de fornecer informações relevantes para que a sociedade possa progredir para a flexibilização dos confinamentos e retomar gradualmente as suas atividades "normais".

Apesar de vários países em parceria com diversas instituições de pesquisa e laboratórios ao redor do mundo já terem desenvolvidos diversas vacinas, o processo de vacinação tem sido lento e desorganizado, contribuindo para a extensão do problema por um período maior de tempo e, de acordo com diversos especialistas ouvidos pela imprensa, mesmo com a disponibilidade dos imunizantes, ainda serão necessários cuidados para evitar a contaminação de outros indivíduos e manter o controle da pandemia.

Além do aumento do número de mortos e infectados, o SARS-CoV-2 tem sofrido mutações em alguns lugares como Londres na Inglaterra, Johanesburgo na África do Sul e Manaus no Brasil que, do ponto de vista biológico, o tem tornado mais eficiente quanto sua dispersão e contaminação de novos hospedeiros.

De acordo com Faria et al. (2021), a nova linhagem encontrada em Manaus contém uma constelação única de mutações definidoras de linhagem, incluindo várias mutações de importância biológica e que o surgimento de variantes com múltiplas mutações compartilhadas no spike, aumenta a preocupação sobre a evolução convergente para um novo fenótipo, potencialmente associado a um aumento na transmissibilidade ou propensão para reinfecção de indivíduos, o que dificulta a perspectiva do retorno às atividades, sem um protocolo adequado que permita as pessoas trabalharem com um mínimo de segurança.

Neste sentido, esse trabalho buscou avaliar a percepção da comunidade acadêmica em uma instituição de ensino superior (IES) na cidade de Manaus quanto à execução do protocolo ambiental e sanitário contra a COVID-19, bem como o atendimento às normas previstas pelos órgãos competentes, identificando os principais aspectos adotados e verificando a progressão da doença.

\section{Metodologia}

Este trabalho foi realizado em uma IES privada, localizada na zona leste da cidade de Manaus, a qual dispõe de 990 alunos matriculados e 72 funcionários entre professores, administrativos, manutenção e limpeza.

De acordo com Pereira et al. (2018), essa pesquisa pode ser classificada como um estudo de caso, sendo de natureza aplicada, com uma abordagem quali-quantitativa, através da análise exploratória e a realização de levantamentos com auxílio de questionário estruturado, contendo 17 questões, sendo duas abertas e 15 fechadas (figura 1).

Ainda segundo o autor, esta metodologia é regularmente aplicada em diversas áreas como a da Saúde, Ciências Sociais, Ambientais dentre muitas outras devido a sua versatilidade e aplicabilidade.

Nesse sentido, este estudo buscou avaliar aspectos referentes à evolução da doença e a percepção dos participantes sobre a atuação a IES quanto essa questão através de uma Escala Likert (Pereira et al., 2018), variando entre 1 e 5 onde: 1Muito Bom; 2-Bom; 3-Regular; 4-Ruim e 5-Muito Ruim bem como aspectos sociais e comportamentais dos participantes. 
Além disso, foram feitas observações sob o protocolo ambiental e sanitário elaborado pela instituição, onde foram verificados os principais aspectos relacionados aos meios de preservação e contenção da disseminação do vírus no ambiente institucional, conforme as recomendações da OMS, o Ministério da Saúde (MS) e a Fundação de Vigilância em Saúde do Amazonas (FVS-AM).

Por fim, foram realizadas visitas para verificar o atendimento às normas estabelecidas pelo protocolo ambientalsanitário institucional, identificando as medidas elencadas e realizadas pela IES.

Os dados obtidos foram tabulados em planilhas eletrônicas e seus valores absolutos foram convertidos em valores relativos, para melhor expressar seus resultados.

Quadro 1 - Síntese do questionário estruturado aplicado durante a pesquisa.

\begin{tabular}{|c|l|}
\hline N & \multicolumn{1}{|c|}{ QUESTÕES } \\
\hline 1 & Gênero \\
\hline 2 & Idade \\
\hline 3 & Função na IES \\
\hline 4 & Forma de condução até a IES \\
\hline 5 & Bairro em que mora \\
\hline 6 & Numero de pessoas que moram na mesma residência \\
\hline 7 & Você ou alguém da sua família já apresentou sintomas correlacionados a COVID-19? \\
\hline 8 & Alguém da sua família já foi diagnosticado com COVID-19? \\
\hline 9 & Você já foi diagnosticado com COVID-19? \\
\hline 10 & Quantas pessoas da IES que você conhece tiveram COVID-19? \\
\hline 11 & Você recebeu orientações da IES com relação ao protocolo ambiental e sanitário adotado? \\
\hline 12 & Com relação ao protocolo, o que você não identificou durante a sua permanência na IES. \\
\hline 13 & Qual o nível de adesão ao protocolo COVID-19 da IES pelas pessoas de um modo geral? \\
\hline 14 & Qual o seu nível de adesão ao protocolo COVID-19 da IES? \\
\hline 15 & Durante as aulas presenciais, você se sentiu seguro em virtude das medidas adotadas pela IES? \\
\hline 16 & Você acredita que já estamos preparados para voltarmos às aulas integralmente presenciais em 2021? \\
\hline 17 & Comentários e sugestões. \\
\hline
\end{tabular}

Fonte: Autores (2020).

\section{Resultados e Discussão}

Foram ouvidas 268 pessoas entre alunos, professores e funcionários da instituição, sendo composta por 58,6\% de mulheres $41,4 \%$ de homens, com $75 \%$ destes jovens entre 18 e 35 anos de idade (Figura 1A), indicando uma população majoritariamente jovem. De acordo com a OMS (2020), essa informação é relevante uma vez que o risco de desenvolvimento da forma severa da doença, aumenta gradualmente a partir dos 40 anos de idade, agravando-se dos 60 em diante.

Desse total, cerca de $60 \%$ dos entrevistados adotam o transporte coletivo como principal meio de transporte até a IES (Figura 1B), o que eleva a preocupação quanto à contaminação pela COVID-19. Troko et al. (2011) observaram haver um aumento significativo das chances de contaminação por doenças respiratórias causadas por vírus, em espaços como trens e ônibus urbanos, uma vez que a circulação de ar pode não ser adequada e a aglomeração e o contato entre pessoas é, praticamente, inevitável, sendo maior o risco quanto maior o tempo exposto a ele.

Em casa, cerca de $62 \%$ dos entrevistados admitiram compartilhar o ambiente com até quatro pessoas, o que pode ser considerado próximo a média calculada para o estado do Amazonas que é de 4,43 indivíduos por domicílio (IBGE, 2011). No entanto, mais de $20 \%$ revelaram morar com seis ou mais pessoas no mesmo domicilio, o que pode aumentar o risco de contágio nessa parcela dos entrevistados (Figura 1C), uma vez que tanto o ambiente como a aglomeração e o tempo de exposição ao risco, demonstraram-se importantes fatores para a contaminação, do ponto de vista epidemiológico. 
Destaca-se que mais de $90 \%$ dos entrevistados revelaram que moram na zona leste da cidade de Manaus, mesma região da IES, principalmente nos bairros São José e Zumbi, com 15,7 e 14,6\% (Figura 1D) dos entrevistados e adjacentes à instituição.

Considerando que o tempo de exposição ao perigo aumenta o risco da contaminação por doenças respiratórias provocadas por vírus, morar próximo à faculdade pode contribuir para um menor tempo de exposição ao risco de contaminação nos coletivos, bem como a substituição desses por caminhadas ou bicicletas podem tornar-se uma opção segura, numa perspectiva epidemiológica.

Além disso, quando observado o número de infectados por 100 mil habitantes por bairro, é possível verificar que os mais citados apresentam médio ou baixo números de casos.

Figura 1 - A comunidade acadêmica na IES avaliada pode ser caracterizada como sendo majoritariamente constituída por jovens (A), que utilizam o transporte público coletivo (B), com densidade habitacional de média a alta (C) e que moram próximo ao local (D).

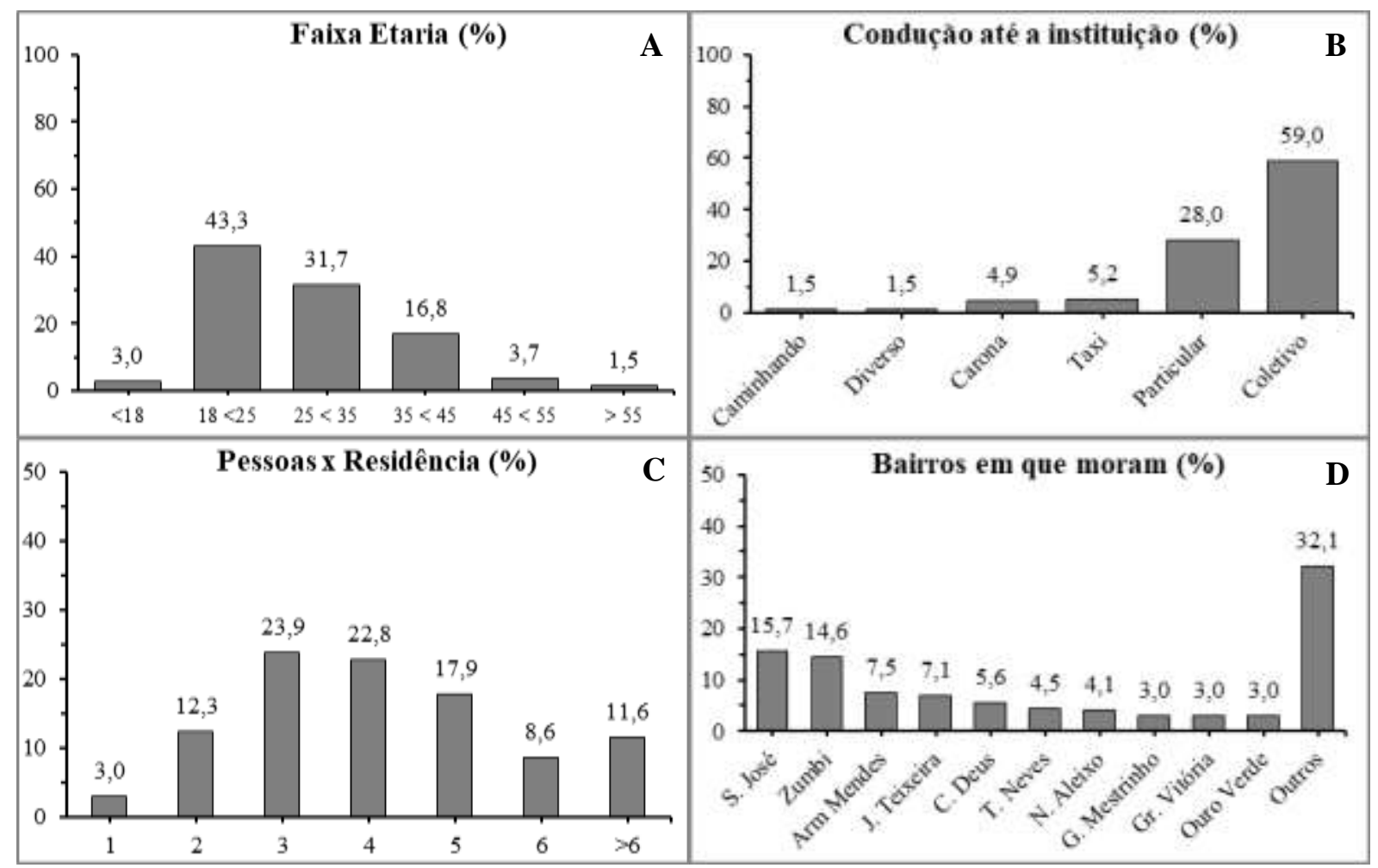

Fonte: Autores (2020).

De acordo com a FVS (2021), bairros como São José, Zumbi e Armando Mendes apresentam 994, 906 e 700 casos por 100 mil habitantes, enquanto Ponta Negra e Centro possuem 2.259 e 3.532, respectivamente (Figura 2), sendo estes últimos os bairros com o maior número de contaminados na capital amazonense até o presente. 
Figura 2 - Casos registrados de COVID-19 em Manaus por 100 mil habitantes, indicando os bairros com maior incidência (1Centro; 2-Ponta Negra) e os com maiores números de moradores que frequentam a IES avaliada nesse estudo (3-Armando Mende; 4-Zumbi; 5-São José).

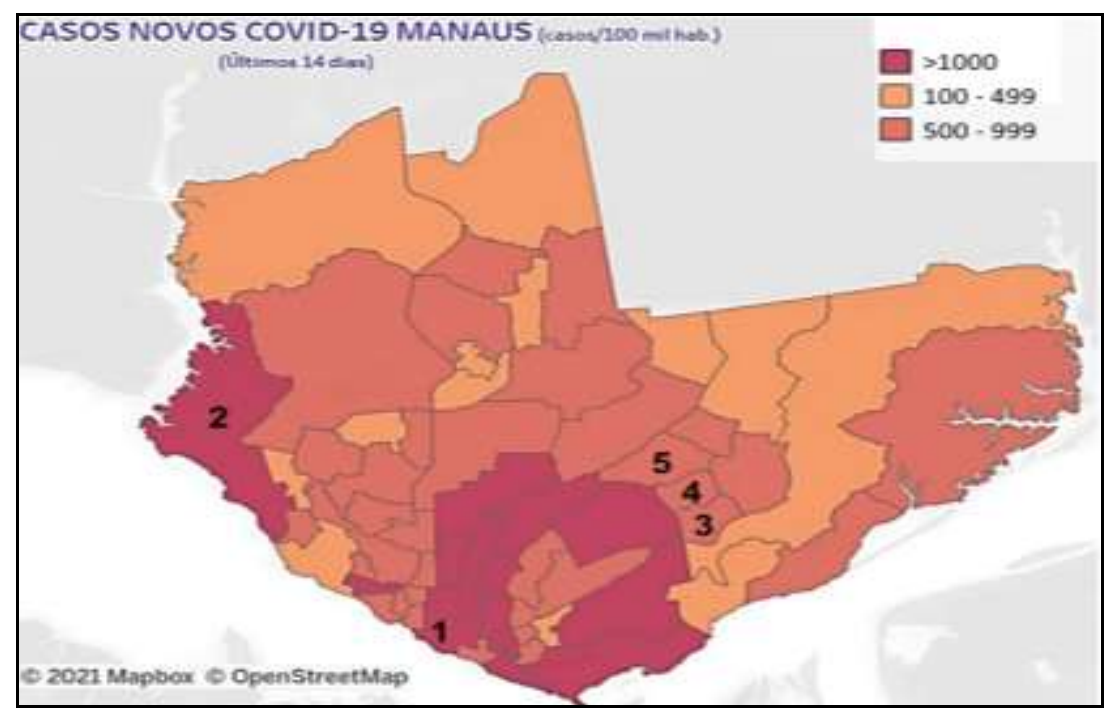

Fonte: FVS-AM (2021).

Durante o período de aula, $65,7 \%$ dos entrevistados informaram não ter sentido nenhum dos sintomas conhecidos da COVID-19 (Figura 3A) e mesmo com 35,8 informando ter tido algum parente diagnosticado (Figura 3B), apenas pouco mais de $10 \%$ informou ter sido diagnosticado com a doença (figura $3 \mathrm{C}$ ), sendo que a maioria (64,2\%) desconhece alguém que tenha adoecido e $84 \%$ disseram conhecer até três pessoas que tiveram contato com o vírus na IES (Figura 3D).

Não foi possível identificar com precisão as datas em que os entrevistados que declararam ter sido diagnosticado com a COVID-19, podendo muitos destes terem sido infectados antes do retorno às aulas presenciais, o que poderia indicar que o percentual de infectados durante o período avaliado neste trabalho possa ser menor do que os valores observados.

Quando relacionados os participantes com as categorias aqui mencionadas, é possível observar alguns aspectos relevantes. Verificou-se que a quantidade de homens e mulheres foi de 14 indivíduos para cada gênero. No entanto, quando observado proporcionalmente, o percentual de contaminados foi superior ao de contaminadas (Tabela 1). Estes dados corroboram com pesquisas desenvolvidas anteriormente onde acredita-se que fatores hormonais e comportamentais como a resistência a utilização correta de máscaras e o fumo, que no Brasil registrou 12,6\% da população como fumantes, sendo distribuídos entre 15,9\% do público masculino e 9,6\% do feminino (INCA, 2021), tornem o homem mais suscetível a doença, sem contar que existe diferenças na resposta imunológica entre homens e mulheres, onde eles desenvolvem uma resposta inflamatória acentuada enquanto elas uma resposta de células T mais eficiente (Takahashi et al., 2020). 
Figura 3 - Distribuição percentual de pessoas com sintomas da COVID-19 (A), parentes diagnosticados com a doença (B), pessoalmente diagnosticado (C) conhecidos na IES (D).

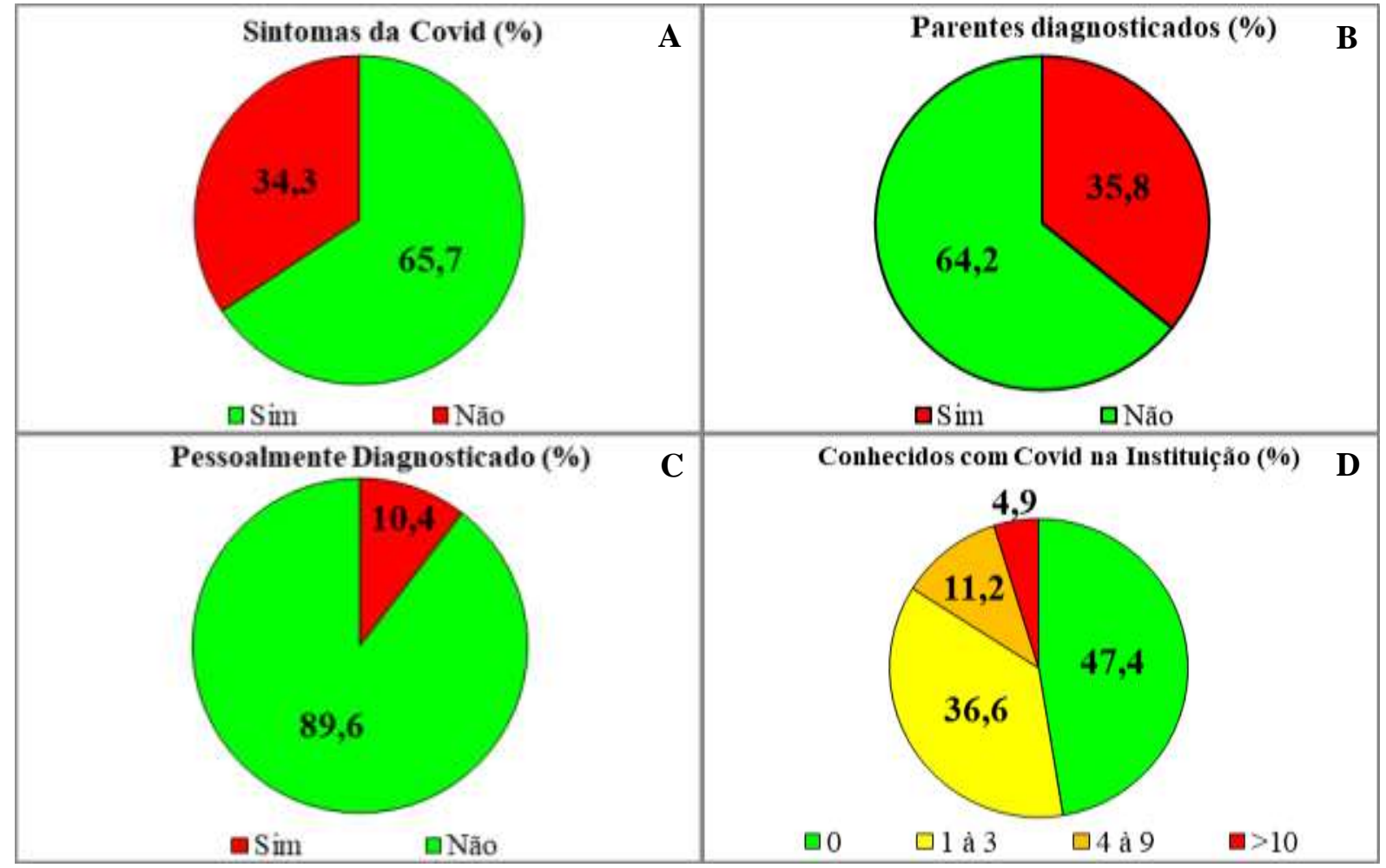

Fonte: Autores (2020).

Quanto a forma de deslocamento, $43 \%$ dos que foram diagnosticados utilizaram algum tipo de transporte coletivo, o que poderia ser considerado "esperado" de acordo com Troko et al. (2011). No entanto, o percentual de pessoas diagnosticadas que utilizam veículos próprios foi superior a todos os outros com mais de 46\%. Acredita-se que a posse de um veículo permita a pessoa visitar mais lugares com mais frequência, do que aqueles que não os possuem como mercado, feiras e lojas, fazendo com que estes se submetam a mais ambientes de risco.

Com relação aos bairros de origem, os três mais populosos observados anteriormente (Figura 2D) foram responsáveis por mais de $30 \%$ do total de diagnosticados. No entanto, quando comparados o número de pessoas por bairro e seu respectivo número de diagnosticados, essa relação os coloca na 17ª (São José), 18 ${ }^{\mathrm{a}}$ (Zumbi) e 19 ${ }^{\mathrm{a}}$ (Armando Mendes) posição dentre os 48 bairros, com maior número de casos.

No caso referente à quantidade de pessoas coabitando em uma mesma residência, dentre aqueles diagnosticados com COVID-19, a maior parte concentrou-se em habitações contendo entre 4 e 5 indivíduos enquanto residência com 6 ou mais pessoas tiveram números menores de infectados. Estes resultados podem indicar que, apesar do maior número de indivíduos por residência, parte desse público pode ser composto por crianças ou idosos, grupos que tem sido menos exposto a situações de risco.

Estes valores aproximam-se da média estimada pelo IBGE (2011) para o Amazonas, porém, distancia-se do que fora observado por Troko et al. (2011) que afirmam que o risco de contrair doenças respiratórias causadas por vírus como o coronavírus, aumenta quanto maior for a densidade de pessoas coexistindo em um mesmo lugar.

Quando questionados se os entrevistados receberam instruções da instituição para como proceder dentro do ambiente acadêmico, 97\% responderam que sim (Figura 4A) e mais de 70\% destes observaram o atendimento a todos os itens do 
protocolo que lhes foi exposto, enquanto alguns não observaram alguns atendimentos como sabão nos banheiros (5,8\%) e outras formas de informação através do sistema de som ou quadro de avisos $(8,2 \%)$ (Figura 4B).

A percepção de que a adesão geral de todos ao protocolo foi positiva, com quase $90 \%$ dos entrevistados descrevendoa como boa ou muito boa (figura 4C) enquanto sua "auto adesão" foi ligeiramente superior com 96,6\% tendo declarado como bom ou muito bom o seu comportamento ante ao cumprimento do protocolo institucional (Figura 4D).

Aparentemente, a percepção de estar atendendo as normas institucionais e observar seus pares também as atendendoas, refletiu-se na sensação de segurança para mais de $83 \%$ dos entrevistados, classificando-a como boa ou muito boa, sendo que e apenas $3 \%$ descreveram-na como ruim ou muito ruim (Figura 6A).

Tabela 1 - Relação entre os participantes diagnosticados com COVID-19 e suas características pessoais e ambientais que podem ter contribuído para sua contaminação.

\begin{tabular}{|c|c|c|}
\hline Parâmetros & Diagnosticados & (\%) \\
\hline \multirow{2}{*}{ Gênero } & Homem & 14,4 \\
\hline & Mulher & 9,8 \\
\hline \multirow{6}{*}{ Faixa Etária } & até 18 & 0,0 \\
\hline & $>18$ e $<25$ & 8,6 \\
\hline & $>25$ e $<35$ & 7,1 \\
\hline & $>35$ e $<45$ & 15,6 \\
\hline & $>45$ e $<55$ & 30,0 \\
\hline & $>55$ & 50,0 \\
\hline \multirow{6}{*}{ Forma de Deslocamento até a IES } & Caminhando & 0,0 \\
\hline & Carona & 3,6 \\
\hline & Coletivo & 42,9 \\
\hline & Táxi & 0,0 \\
\hline & Diverso & 7,1 \\
\hline & Particular & 46,4 \\
\hline \multirow{10}{*}{ Bairro } & Zumbi & 14,3 \\
\hline & São José & 10,7 \\
\hline & Armando Mendes & 7,1 \\
\hline & Cidade Nova & 7,1 \\
\hline & Gilberto Mestrinho & 7,1 \\
\hline & Jorge Teixeira & 7,1 \\
\hline & Nova Cidade & 7,1 \\
\hline & Cidade de Deus & 3,6 \\
\hline & Colônia Antônio Aleixo & 3,6 \\
\hline & Outros & 28,6 \\
\hline \multirow{4}{*}{ Pessoas / Residência } & $1-2$ & 17,9 \\
\hline & $3-4$ & 39,3 \\
\hline & $5-6$ & 39,3 \\
\hline & $>6$ & 3,6 \\
\hline
\end{tabular}


Figura 4 - Percentual de pessoas que receberam algum tipo de orientação sobre o protocolo institucional (A), identificação de não conformidades (B), percepção da adesão geral (C) e Percepção individual (D).

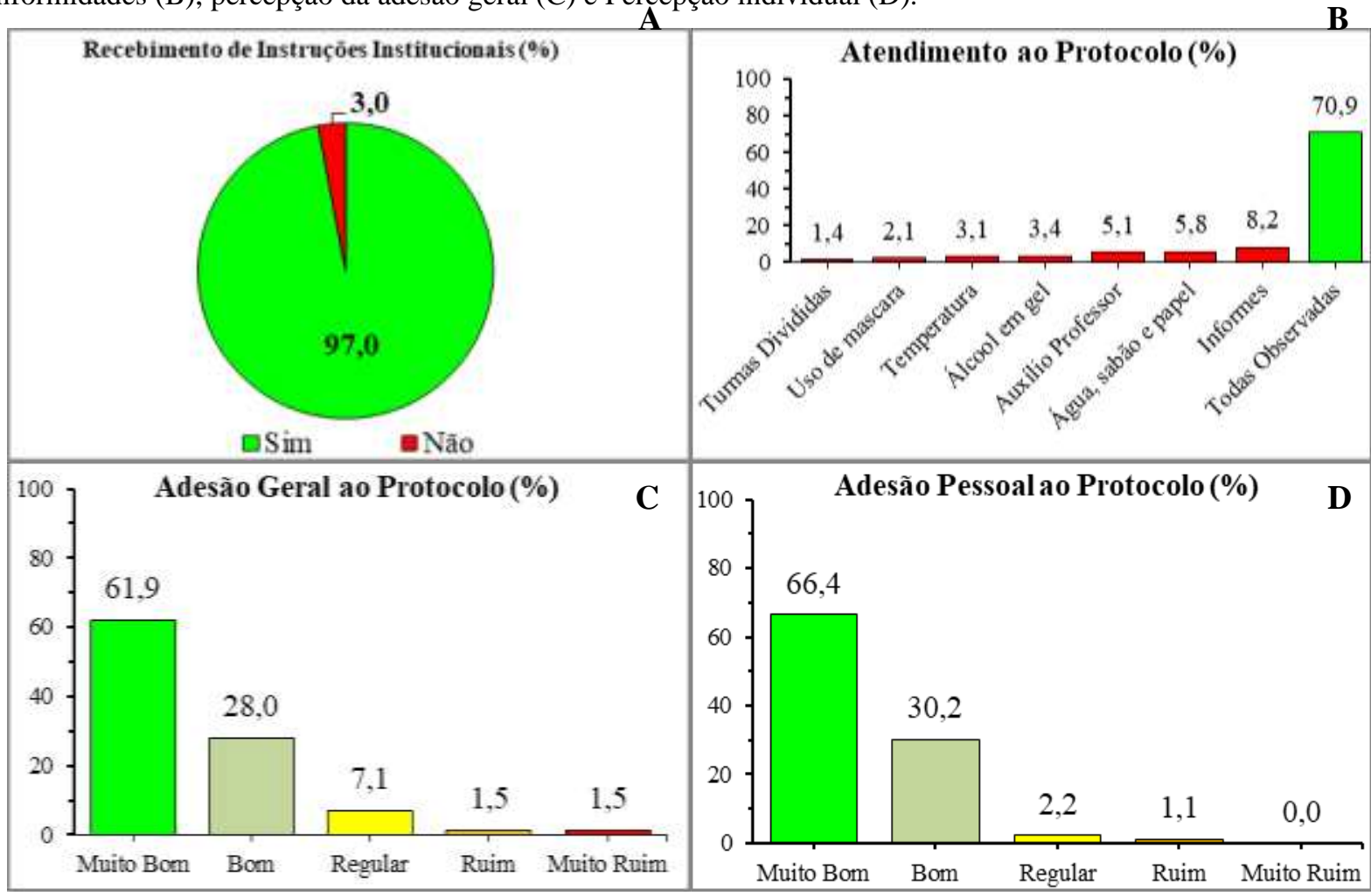

Fonte: Autores (2020).

Aparentemente, a percepção de estar atendendo as normas institucionais e observar seus pares também as atendendoas, refletiu-se na sensação de segurança para mais de $83 \%$ dos entrevistados, classificando-a como boa ou muito boa, sendo que e apenas 3\% descreveram-na como ruim ou muito ruim (Figura 5A).

No entanto, apesar dos números positivos, quando questionado sobre o retorno integral as aulas presenciais com as salas com lotação até $100 \%$ de suas capacidades, notou-se ainda existe um grande receio por parte dos entrevistados que, mesmo entendendo como positivas as medidas e a participação de todos, não seria prudente retornar as aulas de forma integral (Figura 5B).

Figura 5 - Percentual da percepção de segurança da comunidade acadêmica na instituição avaliada (A) e a percepção sobre a instituição retomar suas atividades presenciais completamente (B).

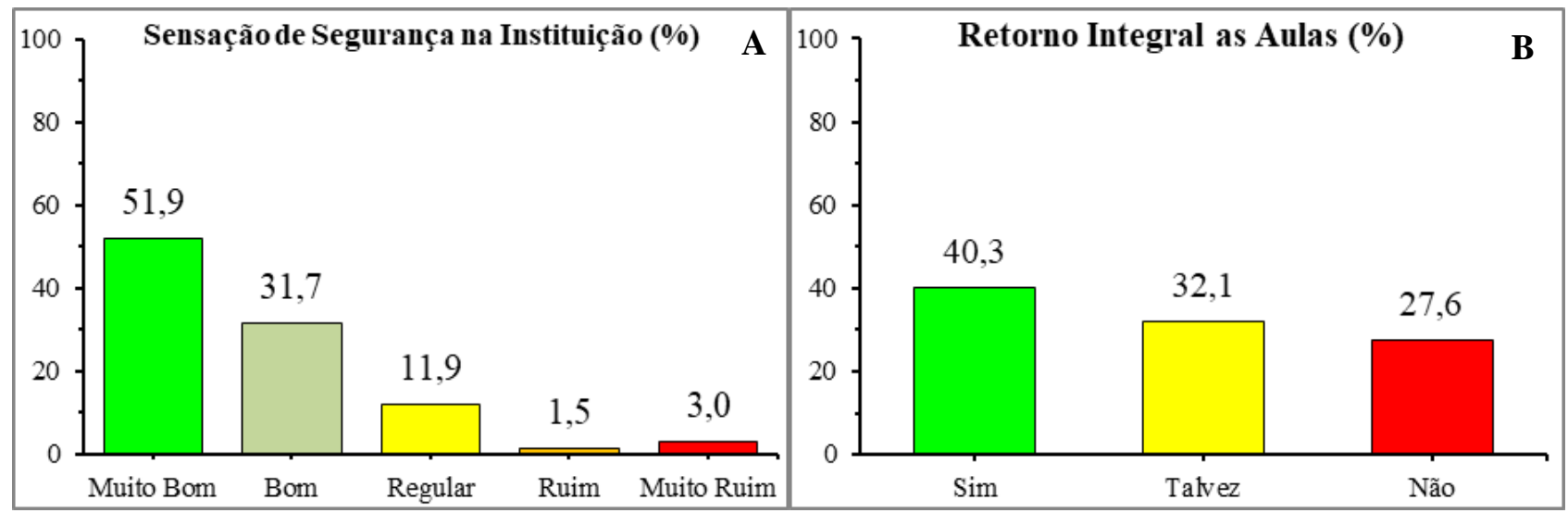

Fonte: Autores (2020). 
Esta preocupação ganha maior relevância em virtude do aumento significativo de casos na cidade entre os meses de dezembro de 2020 e janeiro de 2021, onde o número de casos saltou de 3.379 para 11.041, enquanto o número de óbitos foi de 124 para 819 por semana em apenas três semanas, um aumento de 660\% (Figura 6A) e 327\% (Figura 6B), respectivamente, com uma taxa de mortalidade de 3,5\%, totalizando 7.868 em mortes acumuladas, com $91 \%$ dos leitos de UTI e $94 \%$ dos clínicos ocupados por pacientes da COVID-19 (Figura 8), sendo proporcionalmente maior o número de óbitos do que o de infecção, o que pode sugerir uma maior letalidade causada pela nova variante da cepa encontrada em Manaus (FVS, 2021).

Figura 6 - Variação de casos (A) e de óbitos (B) relacionados à COVID-19 em Manaus.

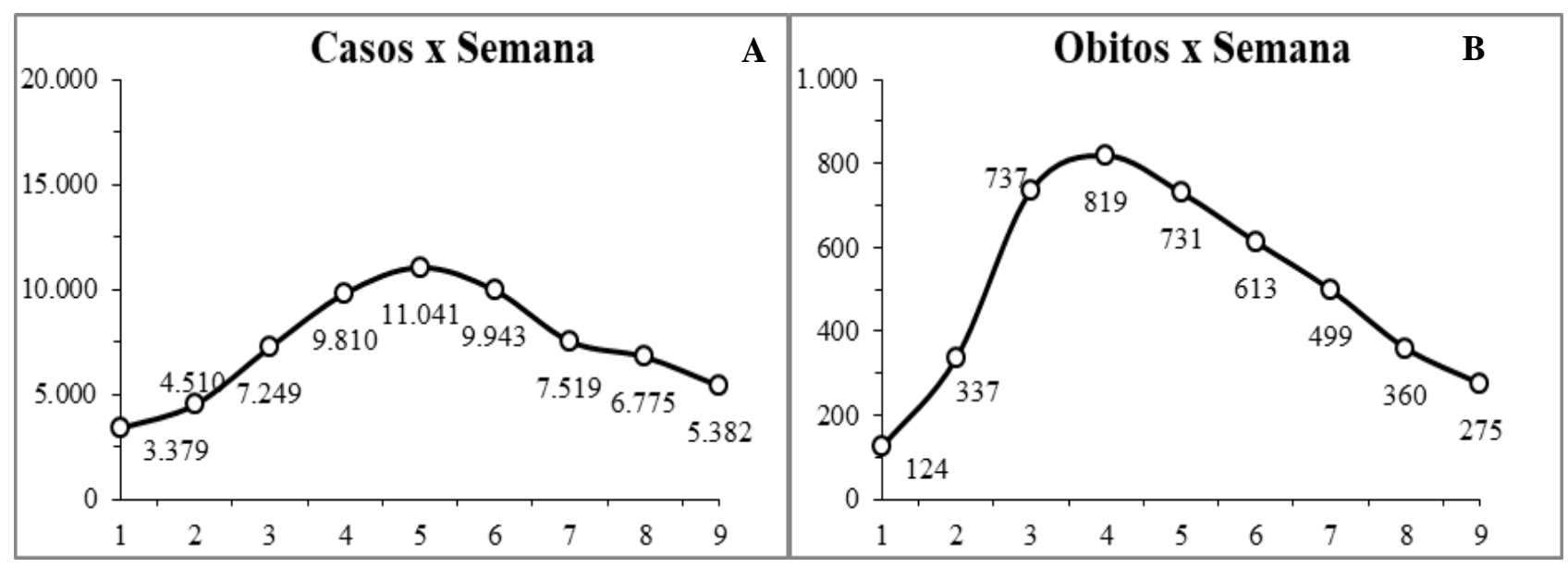

Fonte: FVS (2021).

O protocolo da IES possui sete laudas, tendo toda a orientação dividida em nove itens principais (figura 9), e uma breve apresentação sobre o que se trata o documento intitulado "PROTOCOLO DE HIGIENE E SANITÁRIO DE RETORNO ÀS ATIVIDADES PRESENCIAIS", subdivididas em 76 subitens.

O documento prevê o retorno gradual e escalonado das atividades educacionais, que fora autorizado pelo Governo do Estado do Amazonas, desde que ocorresse "com total cuidado e responsabilidade", levando em consideração um plano permanente de prevenção, monitoramento e controle da transmissão da COVID-19.

Ainda segundo este, o protocolo teve como referência "fundamental" as orientações e recomendações das autoridades de saúde pública como a OMS, o MS e FVS, bem como o Decreto do Governo do Estado do Amazonas No 42.461 de 03 de julho de 2020. No entanto, apenas o decreto foi devidamente referenciado no texto.

Com relação às normas gerais, pode se dizer que esta apresenta as medidas mais divulgadas pela imprensa, comuns e conhecidas pela maioria das pessoas, sejam elas leigas ou profissionais da saúde, indicando como obrigatoriedade a utilização de mascaras, distanciamento mínimo de $1,5 \mathrm{~m}$ entre interlocutores, a ausência de contato físico, a permanência apenas de pessoal essencial no mesmo ambiente e a proibição de eventos "aglomerativos" (apresentações, danças, seminários, confraternizações, etc.), além da diminuição da lotação das salas de aula para apenas 50\% da sua capacidade.

Quanto à higiene pessoal e limpeza dos ambientes, foi solicitado a lavagem frequente das mãos e uso de álcool em gel, além do incentivo e monitoradas permanentemente, a disponibilização de dispensadores de álcool em gel 70\% nas entradas dos blocos e corredores das salas de aulas, cuidado redobrado às rotinas de limpeza dos diversos ambientes (especialmente as áreas de maior circulação, equipamentos e superfícies de uso comum onde ocorre frequente contato com as mãos (carteiras, bancadas, maçanetas, corrimãos, torneiras, interruptores, bebedouros, etc.), bem como os filtros de ar condicionado das salas, intensificação da limpeza dos pisos e calçadas, com produtos de limpeza adequados, limpeza e desinfecção de todas as louças sanitárias existentes, com solução de água sanitária desinfecção programada e realizada por empresa especializada. 
Quadro 2 - Principais itens para a orientação do protocolo institucional contra a COVID-19.

\begin{tabular}{|c|l|}
\hline $\mathbf{N}^{\circ}$ & \multicolumn{1}{|c|}{ ITEM } \\
\hline 1 & Apresentação \\
\hline 2 & 1. Normas gerais e obrigatórias para o retorno às atividades presenciais \\
\hline 3 & 2. Medidas de higiene pessoal e limpeza dos ambientes \\
\hline 4 & 3. Procedimentos que antecedem o retorno às atividades presenciais \\
\hline 5 & $\begin{array}{l}\text { 4. Procedimentos a serem adotados em ambientes especificos (portaria, entrada, salas, biblioteca, } \\
\text { reprografia, laboratórios, administração, cantina e praça de alimentação) }\end{array}$ \\
\hline 6 & 5. orientações aos estudantes \\
\hline 7 & 6. orientações aos colaboradores da manutenção e limpeza \\
\hline 8 & 7. orientações aos colaboradores técnicos-administrativos \\
\hline 9 & 8. orientações aos colaboradores docentes \\
\hline 10 & 9. orientações aos serviços terceirizados \\
\hline
\end{tabular}

Fonte: Autores (2020).

Apesar dos nove itens específicos contidos no documento, seguido pelos 76 subitens, muitas das informações se repetem por serem comuns a todos os outros, o que pode ter tornado o protocolo mais longo do que o necessário e, assim, menos eficiente do ponto de vista da efetividade da comunicação, uma vez que a memória de trabalho e a compreensão da leitura estão diretamente relacionadas e quanto maior for o volume de informação menor será a absorção. Por outro lado, a repetição das mesmas questões ao longo do documento pode contribuir e reforçar na memorização do conteúdo desejado (Farias \& Mourão Jr., 2013), uma vez que os itens “orientações" trazem os mesmos conteúdos gerais como uso de mascara, distanciamento e higiene das mãos, excetuando-se as especificidades de cada público alvo.

Dessa forma, foram elencados os itens mais mencionados no documento (Figuras 7A, 7B, 7C, 7D e 7E), dentre eles, a Medição da temperatura; Álcool em gel disponível e acessível; Placas, letreiros, quadros de avisos, TVs informando sobre a COVID-19 e o Protocolo; Professores falando, comentando ou cobrando o cumprimento do Protocolo; Uso de mascara obrigatório; Água, sabão e papel toalha disponíveis nos banheiros; Turmas divididas ou semipresenciais (metade presencial/metade online); Evitar aglomerações.

Instruções semelhantes foram observadas pela FVS (2020) na elaboração de suas normas para o retorno gradual das atividades educacionais em tempos de pandemia, no caso, a COVID-19, onde foi possível perceber que a IES seguiu estas recomendações.

Durante o levantamento, apenas o item "água, sabão e papel” poderiam ser considerados como alguma "não conformidade" em virtude da equipe ter verificado que, assim como mencionado na figura $5 \mathrm{~B}, 5,8 \%$ informaram ter tido dificuldade de encontrar sabão para lavar as mãos, tendo que se deslocar até outros banheiros em busca desse recurso. 
Research, Society and Development, v. 10, n. 5, e29810513675, 2021

(CC BY 4.0) | ISSN 2525-3409 | DOI: http://dx.doi.org/10.33448/rsd-v10i5.13675

Figura 7 - Avisos para o uso de mascaras e a manutenção da distância mínima entre pessoas foram bem distribuídas por toda a instituição (A), próximas a bebedouros para seu uso correto (B), a entrada principal com vários avisos e recursos (C), dicas de como lavar as mãos de forma correta nos banheiros (D) e totem dispensador de álcool em gel (E) foram algumas das medidas observadas pela equipe de campo.

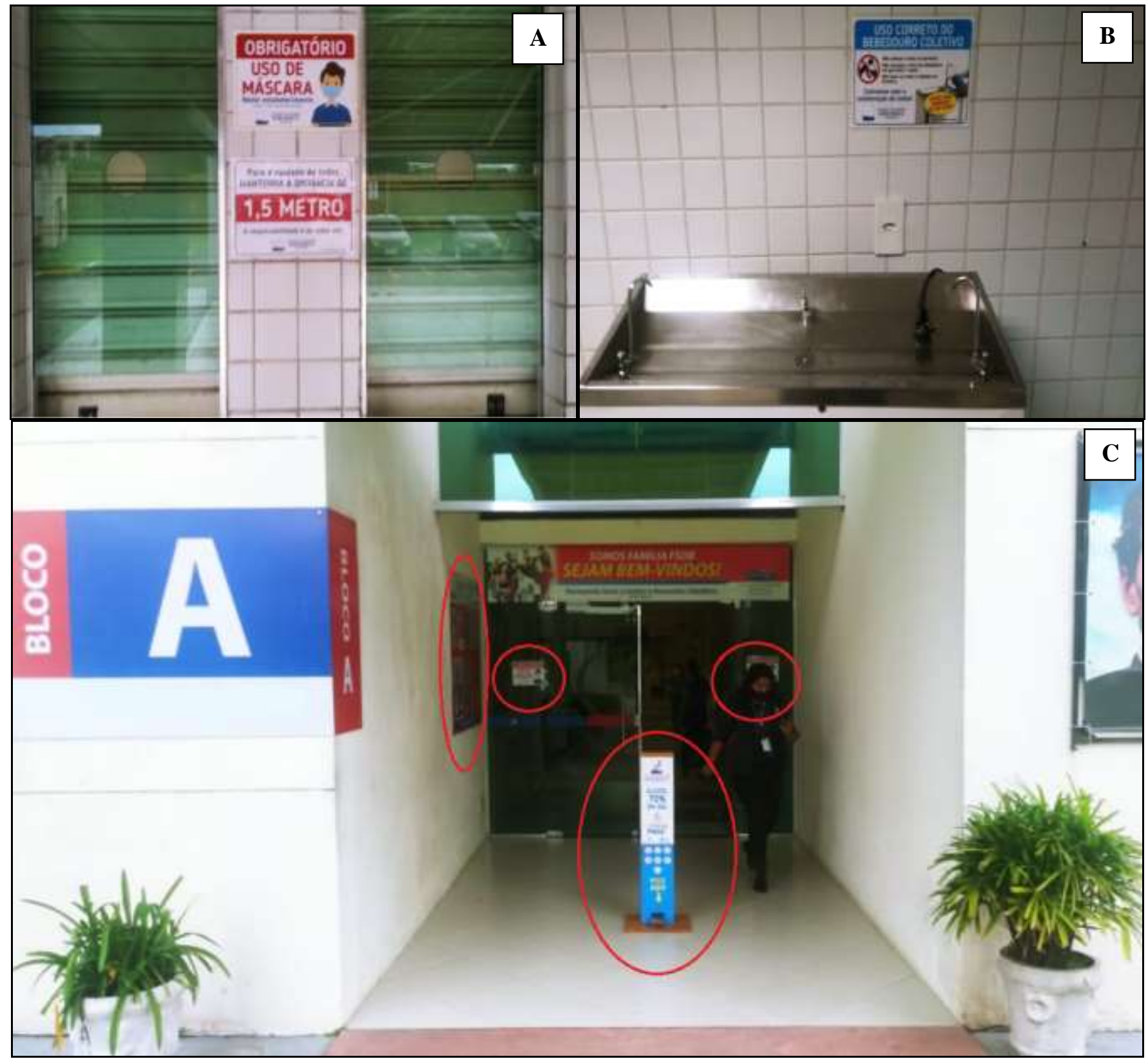




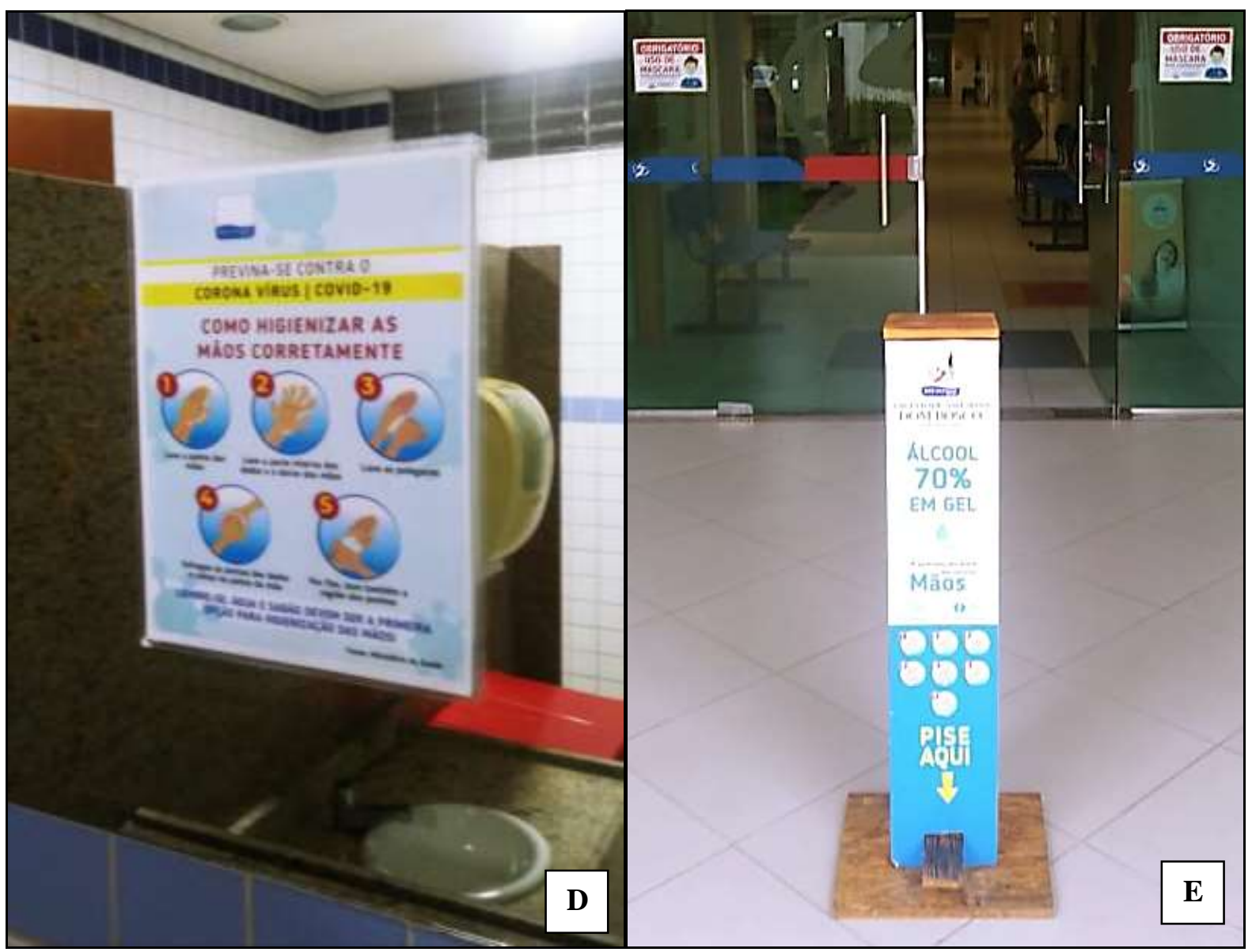

Fonte: Autores (2020).

Quando solicitada à participação livre através de comentários ou sugestões por parte dos entrevistados, apenas 56 de um total de 268 indivíduos (20,9\%) fizeram suas contribuições, sendo aproximadamente 52\% contendo aspectos positivos e $48 \%$ negativos ou contendo sugestões para a melhoria do protocolo ou sua execução e fiscalização (Tabela 2).

Com relação aos aspectos positivos, a maioria dos comentários repousou sobre o atendimento às normas elaboradas por outras instituições que a IES adotou, inclusive, alunos que trabalham em empresas do Polo Industrial de Manaus (PIM) identificaram como "semelhantes" os protocolos bem como a sensação de segurança causada por estes.

Quanto às sugestões ou aspectos negativos identificados, a maioria alegou o comportamento individual como sendo um dos principais obstáculos para o sucesso do protocolo, uma vez que diversos dos comentários foram sobre o contato físico frequente, desrespeito ao distanciamento, o uso incorreto de mascaras ou a falta de uso delas até mesmo por professores, indicando que, talvez, seria interessante a instituição disponibilizar um canal adequado para que as pessoas pudessem denunciar estas ocorrências, contribuindo, assim, para o aumento da eficácia das medidas adotadas pela IES neste protocolo. 
Tabela 2 - Síntese de respostas livres dos participantes contendo comentários e sugestões.

\begin{tabular}{|c|c|c|}
\hline \multicolumn{3}{|c|}{$\begin{array}{c}\text { Participação Livre } \\
\text { (Comentários/Sugestões) }\end{array}$} \\
\hline $\mathbf{N}$ & Aspectos Positivos & Aspectos Negativos \\
\hline 1 & $\begin{array}{c}\text { "A faculdade observou todas as medidas possíveis } \\
\text { impostas pelas autoridades. Estou satisfeito e me sinto } \\
\text { seguro em estudar na instituição". }\end{array}$ & $\begin{array}{c}\text { "Ainda existem muitos casos de covid para voltarmos à } \\
\text { aglomeração". }\end{array}$ \\
\hline 2 & $\begin{array}{l}\text { A faculdade tem uma ótima condição para realização de } \\
\text { aulas presenciais, não tenho reclamações. }\end{array}$ & $\begin{array}{l}\text { "É necessário maior fiscalização para alunos e } \\
\text { funcionários". }\end{array}$ \\
\hline 3 & $\begin{array}{l}\text { "A instituição atuou muito bem no combate a não } \\
\text { proliferação do COVID-19, a divisão de grupos foi muito } \\
\text { bem feita tendo em vista que quando um aluno se sentia } \\
\text { indisposto ou com algum sintoma parecido com o do vírus } \\
\text { da COVID-19, optava por ficar em sua residência, sem } \\
\text { risco de se contaminar ou de contaminar alguém". }\end{array}$ & $\begin{array}{c}\text { "Nem todos os professores usavam mascaram durante as } \\
\text { aulas. Revejam isso!". }\end{array}$ \\
\hline 4 & $\begin{array}{c}\text { "A instituição é uma faculdade excelente, e nesse } \\
\text { momento tão difícil que estamos passando nos mostrou } \\
\text { que está sempre preparada". }\end{array}$ & $\begin{array}{c}\text { "Sugiro que cobrem mais o distanciamento dentro de sala } \\
\text { de aula. E o uso de máscara correto. Observei muitos } \\
\text { alunos com mascara na boca e não no nariz". }\end{array}$ \\
\hline 5 & $\begin{array}{l}\text { "Acredito que o jeito em que está sendo ministradas as } \\
\text { aulas tem sido uma ótima escolha nesse momento em que } \\
\text { passamos, onde são metade online e metade presencial". }\end{array}$ & $\begin{array}{l}\text { "Não deixar faltar papel ou sabonete nos banheiros, pois } \\
\text { sempre tive que ficar de banheiro em banheiro para vê qual } \\
\text { tinha". }\end{array}$ \\
\hline
\end{tabular}

Fonte: Autores (2020).

Apesar dos resultados gerais obtidos nessa pesquisa aparentemente serem positivos e até animadores, outra realidade se impõe através do surgimento de novas variantes do "novo Corona vírus", como a linhagem "P.1", detectada circulando desde dezembro em Manaus, onde taxas de ataque muito altas foram estimadas anteriormente. Esta nova linhagem, contém uma constelação única de mutações definidoras de linhagem, incluindo várias mutações de importância biológica conhecida, sugerindo uma transmissão local e, possivelmente, aumento recente na frequência de uma nova linhagem da região amazônica. A maior diversidade e as datas de amostragem anteriores de P.1. em Manaus corrobora as informações de viagem de casos detectados recentemente no Japão, sugerindo que o sentido da viagem era de Manaus para o Japão.

O recente surgimento de variantes com o compartilhamento múltiplo de mutações no "spike" levanta preocupação sobre a evolução convergente para um novo fenótipo, potencialmente associado com um aumento na transmissibilidade ou propensão para reinfecção de indivíduos (Faria et al., 2021), o que pode ter contribuído para o colapso recente do sistema de saúde do estado do Amazonas.

De acordo com Sridhar e Gurdasani (2021), espera-se que a imunidade do rebanho surja quando um vírus não pode se espalhar prontamente, porque encontra uma população que tem um nível de imunidade que reduz o número de indivíduos suscetíveis à infecção. No entanto, mesmo com uma estimativa de $76 \%$ da população infectada, aparentemente, a imunidade coletiva não foi alcançada, sugerindo que a imunidade de rebanho provavelmente não é alcançada mesmo com altos níveis de infecção.

Ainda segundo os autores, a reinfecção com SARS-CoV-2 sugere que a infecção primária pode não conferir de forma consistente imunidade de longo prazo a todos os infectados, podendo esta diminuir com o tempo e, os indivíduos expostos podem voltar a se tornar suscetíveis, criando uma nova população suscetível que pode então contribuir para a transmissão e que sem medidas rígidas de controle, a epidemia continuaria a se acelerar por muitos meses com um alto custo em virtude das mortes que ocorreriam em busca da imunidade, uma vez que permanecem grandes incógnitas sobre quanto tempo dura a imunidade ao SARS-CoV-2 e o risco de reinfecção. 
De acordo com Isphording, Lipfert e Pestel (2020), a reabertura de escolas na Alemanha sob medidas de higiene combinadas com distanciamento social e medidas de contenção não aumentaram o número de infecções por SARS-CoV-2, indicando que a reabertura de escolas pode ser segura.

Parshley (2020) afirma que os jovens são menos propensos a contrair e dispersar a doença do que adultos. Além disso, o risco de transmissão dentro de residências durante o confinamento foi maior do que entre contatos casuais típicos entre jovens em ambiente escolar como no caso da Suíça, em que foi observado que crianças entre cinco e nove anos tinham até 22,7\% menos probabilidade de serem contaminadas e o risco aumentava conforme a idade, indicando que a principal mudança ocorre entre os 10 e 12 anos, levando a crer que esta resistência possa se dar em virtude de que as crianças são expostas com mais frequência a outros tipos de coronavírus, conferindo-lhes certa proteção, ou que as crianças possuam menos receptores de ECA2, alvo do novo coronavírus, em suas vias aéreas superiores ou ainda por que pulmões menores não expelem tantas gotículas nem geram tantos aerossóis, quanto pulmões maiores, por exemplo.

$\mathrm{O}$ autor reitera que a transmissão não depende apenas de fatores biológicos, mas também de fatores ambientais e comportamentais, como observado na Índia, onde foi encontrado padrões de maior risco de transmissão do novo coronavírus em menores de 14 anos, incluindo muitos casos em que crianças foram contaminadas por outras crianças.

Como observado nesse estudo, $75 \%$ da população amostral pode ser considerada como sendo de jovens (figura 2A), o que, a princípio, pode soar como um aspecto positivo. E, na verdade, o é, tendo em vista que a maioria das mortes e internações concentra-se em pessoas mais velhas ou com comorbidades (Escobar, Rodriguez \& Monteiro, 2020).

No entanto, esse grupo corresponde a idades que variam entre 16 e 35 anos, o que seria uma faixa etária superior àquela observada como "mais resistente" ao novo coronavírus, demandando, assim, maior atenção no cumprimento dos protocolos.

Com o advento das vacinas que vem sendo desenvolvidas em todo o mundo e algumas sendo aplicadas, inclusive no Brasil, espera-se que este cenário sofra uma mudança positiva no que se refere aos diversos aspectos inerentes as restrições provocadas pela pandemia.

Até termos uma ampla disponibilidade de vacinas, é provável que o SARS-CoV-2 continuará a causar surtos, exigindo novas rodadas de distanciamento social e proteção a grupos suscetíveis. Máscaras serão obrigatórias em espaços públicos e eventos (Romano; Chebabo \& LEVI, 2020).

No entanto, este processo ainda será longo e as medidas de controle adotadas pelas instituições como esta, aqui observada, ainda deverão perdurar por tempo indeterminado, uma vez que a rápida propagação da doença exige protocolos de investigação e isolamento para evita-la adicional (Milibari, 2020) para que assim possamos, de forma definitiva, retornar de forma integral a todas as atividades que eram desenvolvidas antes da pandemia causada pela COVID-19.

\section{Considerações Finais}

As ações praticadas pela IES foram positivas e contribuíram para o controle da doença dentro do ambiente institucional, fazendo com que a comunidade acadêmica se sentisse segura.

Apesar do resultado positivo, foram observadas algumas não conformidades quanto ao cumprimento de alguns itens do protocolo, devendo a instituição intensificar a fiscalização sobre esses aspectos para que o bom resultado seja mantido.

Apesar da sensação de segurança compartilhada por quase todos, à volta as aulas de forma integral (100\% presencial) ainda é polêmica, dividindo opiniões dentro da comunidade acadêmica, que se sente mais confortável com a manutenção do protocolo adotado pela IES, de aulas com 50\% dos alunos presencial e 50\% dos alunos remoto, como vinha sendo executada.

No entanto, em virtude da crise na área da saúde observada na cidade de Manaus e a lentidão no processo de vacinação, recomenda-se que as aulas sejam suspensas ou realizadas de forma integralmente remotas, enquanto os números de 
casos e óbitos não regredirem a níveis aceitáveis/controláveis ou que a taxa de infecção observada pelas autoridades sanitárias seja inferior a "1" ou que a vacinação da população não progrida conforme o esperado.

Para estudos futuros, sugere-se o aprofundamento de questões socioeconômicas para aumentar a base de informações de forma que permitam delinear um perfil mais preciso dos participantes, refinando e possibilitando identificar com maior precisão os grupos mais relevantes.

\section{Referências}

Ahmed, S. S. (2020). The Coronavirus Disease (COVID-19): A Review. In: Journal of Advances in Medicine and Medical Research. 32(4), 1-9.

Escobar, A. L., Rodriguez, T. D. M. \& Monteiro, J. C. (2020). Letalidade e características dos óbitos por COVID-19 em Rondônia: estudo observacional. Epidemiol Serv Saúde https://doi.org/10.1590/s1679-49742021000100018.

Faria, E. L. B. \& Mourão JR, C. A. (2013). Os recursos da memória de trabalhos e suas influências na compreensão da leitura. In: Psicologia: Ciência e Profissão, 33(2), 288-303.

Faria, N. R., Claro, I. M., Candido, D., Franco, L. A. M., Andrade, P. S., Coletti, T. M., Silva, C. A. M., Sales, F. C., Manuli, E. R., Aguiar, R. S., Gaburo, N., Camilo, C. C., Fraiji, N. A., Crispim, E. M. A., Carvalho, M. P. S. S., Rambaut, A., Loman, N., Pybus, O. \& Sabino, E. C. (2021). Genomic characterisation of an emergent SARS-CoV-2 lineage in Manaus: preliminary findings. In: Virological - A discussion forum for analysis and interpretation of virus molecular evolution and epidemiology. de https:// virological.org/t/genomic-characterisation-of-an-emergent-sars-cov-2-lineage-in-manaus-preliminaryfindings/586/print

Fundação Oswaldo Cruz - FIOCRUZ. (2020). NOTA TÉCNICA N. ${ }^{\circ}$ 1/2020/PG-EBS/IOC-FIOCRUZ. Embasamento técnico e sugestões para ações de promoção da saúde ambiental e estratégias educacionais para mitigar as iniquidades no acesso à Educação Básica no Brasil no contexto da pandemia de COVID-19. 23p.

Fundação Vigilância em Saúde do Amazonas - FVS-AM. (2020). COVID-19: Normas e recomendações para o retorno gradual das atividades educacionais. 13 .

Fundação Vigilância em Saúde do Amazonas - FVS-AM. (2021). Painel COVID-19 no Amazonas. http://www.saude.am.gov.br/painel/corona/

Lima, C. M. A. O. (2020). Informações sobre o novo coronavírus (COVID-19). In: Radiol Bras. 53(2). 5-6.

G1AM. (2021). Em dois meses de 2021, Manaus tem mil mortes a mais do que em 2020: Na capital, o número geral de enterros cresceu mais de seis vezes em 2021. https://g1.globo.com/am/amazonas/noticia/2021/03/03/em-dois-meses-de-2021-manaus-tem-mil-mortes-a-mais-do-que-em-2020.ghtml

Instituto Nacional de Câncer - INCA. (2021). Dados e números da prevalência do tabagismo. In: Observatório da Política Nacional de Controle do Tabaco. https://www.inca.gov.br/observatorio-da-politica-nacional-de-controle-do-tabaco/dados-e-numeros-prevalencia-tabagismo

Milibari, A. A. (2020). Currente situation of Coronavirus Disease: (COVID-19) Review Article. In: Helth e Science Journal. p.1-4.

Ministério da Saúde - MS. (2021). Covid no Brasil. In: SUS Analítico. https://susanalitico.saude.gov.br/extensions/covid-19_html/covid-19_html.html

Mohamed, H. M., Ahmed, S. A., Hussein, A. M., Ahmed, S. A. A., Mohamed, I. I. \& Sheikh, A. M. (2020). The Impact of Coronavirus (COVID-19) on Higher Education Case Study Private Universities in Mogadishu, Somalia. In: Creative education. 11. 2249-2261.

Oliveira, J. (2020). Diplomas de 1,6 milhão de estudantes ameaçados pela Reforma Tributária. In: Estado de Minas. https://www.em.com.br/app/noticia/educacao/2020/12/21/internas_educacao,1222560/diplomas-de-1-6-milhao-de-estudantes-ameacados-pela-reformatributaria.shtml

Organização Mundial da Saúde - OMS. (2020). Coronavirus disease (COVID-19) pandemic: Advice for the public, country and technical guidance. https://www.who.int/emergencies/diseases/novel-coronavirus-2019

Organização Mundial da Saúde - OMS. (2020). Coronavirus disease 2019 (COVID-19) Situation Report - 51. https://www.who.int/docs/defaultsource/coronaviruse/situation-reports/20200311-sitrep-51-covid-19.pdf?sfvrsn=1ba62e57_10

Parshley, L. (2020). The emerging long-term complications of Covid-19, explained. https://www.vox.com/2020/5/8/21251899/coronavirus-long-term-effectssymptoms

Pereira A. S., Shitsuka, D. M., Parreira, F. J. \& Shitsuka, R. (2018). Metodologia da pesquisa científica. UFSM. 119p. https://repositorio.ufsm.br/bitstream/handle/1/15824/Lic_Computacao_Metodologia-Pesquisa-Cientifica.pdf?sequence=1

Romano, C. M., Chebabo, A. \& Levi, J. E. (2020). Past, present, and future of COVID-19: a review. In: Brazilian Journal of Medical and Biological Research. 53(9). p.1-8.

Sindicato das Entidades Mantenedoras de Estabelecimentos de Ensino Superior no Estado de São Paulo - SEMESP. (2020). Inadimplência e evasão nas instituições de ensino superior privadas. Pesquisa SEMESP. 1p.

Sridhar, D. \& Gurdasani, D. (2021). Herd immunity by infection is not an option: Difficult lessons are learned from a largely uncontrolled COVID-19 epidemic in Manaus, Brazil. In: Science. 371(6526), 230-231. 
Research, Society and Development, v. 10, n. 5, e29810513675, 2021

(CC BY 4.0) | ISSN 2525-3409 | DOI: http://dx.doi.org/10.33448/rsd-v10i5.13675

Takahashi, T., Ellingson, M. K., Wong, P., Israelow, B., Lucas, C., Klein, J., Silva, J., Mao, T., Oh, E. J., Tukuyama, M., Lu, P., Venkataraman, A., Park, A., Liu, F., Meir, A., Sun, J., Wang, E. Y., Casanovas-Massana, A., Wyllie, A. L., Vogels, C. B. F., Earnest, R. ; Lapidus, S., Ott, I. M., Moore, A. J., Shaw, A., Fournier, J. B., Odio, C. D., Farhadian, S., Cruz, C. D., Grubaugh, N. D., Schulz, W. L., Ring, A. M., Ko, A. I., Omer, S. B. \& Iwasaki, A. (2020). Sex differences in immune responses that underlie COVID-19 disease outcomes. In: Nature, 588(10), 315-333.

Troko, J., Myles, P., Gibson, J., Hashim, A., Enstone, J., Kingdons, S., Packham, C., Amin. S., Hayward, A. \& Van-Tam, J. N. (2021). Is public transport a risk factor for acute respiratory infection? In: BMC Infectious Diseases. 11(16), 11-16.

Vieira, J. M., Ricardo, O. M. P., Hannas, C. M., Kanadani, T. C. M., Prata, T. S. \& Kanadani, F. N. (2020). What do we know about COVID-19? A review article. REV ASSOC MED BRAS. 66(4), 534-540. 